\title{
The role of Montanide ISA 70 as an adjuvant in immune responses against Leishmania major induced by thiol-specific antioxidant-based protein vaccine
}

\author{
Narges Khabazzadeh Tehrani $\cdot$ Mehdi Mahdavi • \\ Fatemeh Maleki • Somayeh Zarrati • \\ Fatemeh Tabatabaie
}

Received: 14 April 2014/Accepted: 8 September 2014/Published online: 20 September 2014

(C) Indian Society for Parasitology 2014

\begin{abstract}
Leishmaniasis is a parasitic disease caused by several species of the genus Leishmania. Montanide ISA 70 is an adjuvant composed of a natural metabolizable oil and a very refined emulsifier from the manide monooleate family. The TSA (thiol-specific antioxidant) is a important antigen of Leishmania major. The purpose of this work was proteinvaccine efficacy as an protection and excellent candidate in the presence Montanide. The expression of recombinant protein was confirmed with SDS (sodium dodecyl sulfate) page and Western bloting. $48 \mathrm{BALB} / \mathrm{c}$ mice were divided into four groups (TSA/Freund,TSA/Alum + BCG, TSA/ Montanide and PBS groups) and immunized with $20 \mu \mathrm{g}$ of vaccine subcutaneously three times intervals on days 0,14 and 28 . The mice were challenged with parasite 21 days after final immunization. The lymphocyte proliferation was evaluated with Brdu method. Cytokines and also total antibody and subclasses were evaluated with ELISA method. The vaccine formulated with the recombinant TSA protein with Montanide induced lymphocytes proliferation cytokines and total antibody and subclasses as compared with the control group.
\end{abstract}

N. Khabazzadeh Tehrani $\cdot$ S. Zarrati

Biology Dept, Science \&Research Branch, Islamic Azad University, Tehran, Iran

M. Mahdavi

Immunology Dept, Pasteur Institute of Iran, Tehran, Iran

F. Maleki

Faculty of Allied Medicine, Iran University of Medical Sciences

(IUMS), Tehran, Iran

F. Tabatabaie $(\bowtie)$

Parasitology and Mycology Dept., School of Medicine, Iran

University of Medical Sciences(IUMS), Tehran, Iran

e-mail: tabatabaei.f@iums.ac.ir; dr.f.taba@hotmail.com
Keywords BCG $\cdot$ TSA $\cdot$ Montanide $\cdot$ Leishmaniasis . Vaccine $\cdot$ IFN- $\gamma$

\section{Introduction}

Leishmaniasis is caused by parasitic protozoa of the genus Leishmania which, in the infected host are obliging intracellular parasite. In this group Leishmania major is the etiological agent of cutaneous leishmaniasis that is prevalent in many tropical and subtropical areas of the world. The disease has a high incidence rate in Iran (Alvar et al. 2012; Farahmand et al. 2011). The manifestation of disease is varying from self-limiting with life-long immunity to developing shape as chronic disease. When Leishmaniasis accompanied by deficient cellular immunity, the disease can improve to chronic shape (Von Stebut 2007; Douba et al. 2012).The number of new cases of cutaneous leishmaniasis is estimated a range from 0.7 to 1.2 million. The HIV (human immunodeficiency virus) and Leishmania co infection is reason of rapidly growing of Leishmaniasis in regions where Leishmania species are endemic. In the other hand toxicity of chemotherapy and currently available drugs for treatment haven't shown ideal consequence and ever important, resistance to current drugs, above all things underline to need for a safe, effective vaccine (Coler and Reed 2005; Masina et al. 2003). In recent years with completion of genome sequencing of $L$. major, researchers find out that some of genes are expressed in the infectious stages of the parasite and in particular, in amastigotes, which can help to design effective vaccines (khamesipour et al. 2006). Among L. major antigens as vaccine candidate, TSA (thiolspecific-antioxidant) with molecular weight of $22.1 \mathrm{kDa}$ has been introduced as one of the predominant and one of 
the important immune system stimulator, homologue to eukaryotic TSA protein. Recombinant form of TSA protein composed of 200 amino acids and placed in the chromosome of 15 of L. major and is full gene with multiple copy in chromosome. Distribution of TSA protein on the surface of both extracellular and intracellular promastigote and amastigotes is important and in BALB/c mice model infected with $L$. major can persuade Th1 response comparing to the other selected antigens. TSA protein induces strong cellular immune response resulted in protective immunity (mauel 2002; Campos-Neto et al. 2001,2002; Webb et al. 1998). Montanide (Incomplete Seppic adjuvants), is an oil adjuvant composed of a natural metabolizable oil and a highly refined emulsifier from the manide monooleate family. Montanide incomplete seppic adjuvants, are a group of oil/ surfactant based adjuvants in which different surfactants are combined with either a non-metabolizable mineral oil, a metabolizable oil, or a mixture of the two oils. Vaccine formulations with Montanide induce a strong and long term immunity. Compared to traditional oil emulsions, Montanide emulsions are stable and easy to inject which are having high immunopotentiation capacity and showing lesser side-effects are valid (Aucouturier et al. 2001, 2002; Toledo et al. 2001; Joshua et al. 2010). In this report we described novel protein vaccine immune responses elicited.

\section{Material and method}

Expression and purification of the recombinant TSA protein

TSA sequence was optimized and then the sequence was purchased from Biomatik Company (Canada). TSA gene was double digested and after purification of gene, it was subcloned into the pET28a expression vector using ligase enzyme. In order to express the recombinant protein, pET28a-TSA expression vector was transformed into the E. coli BL21 (DE3) using electroporation technique. Culture of E. coli BL21 (DE3) containing pET28a-TSA recombinant plasmid was done in the present of IPTG $1 \mathrm{mM}$ for $4 \mathrm{~h}$. The expression of recombinant protein was confirmed with SDS-PAGE and also via Western blot technique. Recombinant protein was purified with nickel affinity chromatography (Tabatabaie et al. 2007; Bradford, 1976).

Preparation adjuvant

Montanide $70 \mathrm{VG}$ (Seppic france) was used at an adjuvant mixtured with antigen at ratio of $30 / 70(\mathrm{v} / \mathrm{v})$ according to the manufacturer's instructions.
The MHRO/IR/75/ER (an Iranian strain to be isolated by Nadim et al. in 1964) of L. major was provided by Pasteur Institute of Iran. Promastigotes were grown at $26{ }^{\circ} \mathrm{C}$ in RPMI1640 medium (Sigma ${ }^{\circledR}$ ) supplemented with $10 \%$ heat inactivated fetal calf serum $\left(\right.$ Gibco $^{\circledR}$, BRL), and $100 \mu \mathrm{g} / \mathrm{ml}$ gentamicine $\left(\right.$ Sigma $\left.^{\circledR}\right)$. Stationary phase of the promastigotes was harvested at a density of $2 \times 10^{6} / \mathrm{ml}$.

Immunization and experimental infection of the mice

Fourty eight Female inbread BALB/c (6-8 weeks old) mice were purchased from Iran's Razi Serum and Vaccine Production Research Institute and maintained under standard conventional conditions.

The mice were grouped based on administration content as follows in 4 groups:

TSA/Montanide, TSA/BCG-Alum, TSA/Freund and control PBS groups. Twelve mice in each group were anesthetized with $25 \mu \mathrm{L} \mathrm{g}^{-1}$ of mixture of ketamin $10 \%$ and xylazin $2 \%$ via intraperitoneal (i.p.) injection and were immunized with $100 \mu \mathrm{L}$ of administration content according to their grouping $(20 \mu \mathrm{g}$ of recombinant protein TSA vaccine and $40 \mu \mathrm{g}$ of adjuvants) subcutaneously three times intervals on days 0,14 and 28. Finally,immune responses 3 weeks after the last injection were valuated. The mice were challenged at the base of tail by the intradermal route with $2 \cdot 10^{6}$ promastigotes of $L$. major 21 days after final immunization. The Immune responses 3 weeks after challenge were valuated (Rosado-Vallado et al. 2005).

\section{Cell preparation}

Responses of specific and proliferation lymphocytes to Brdu technique was done. Spleen was removed from euthanized mice 3 weeks after the last immunization and 3 weeks after the challenge infection. The tissues were macerated and washed in RPMI 1640 and incubated for five minutes in $0.17 \mathrm{M}$ Tris $\mathrm{pH} 7.2$ and $0.16 \mathrm{M} \mathrm{NH} 4 \mathrm{Cl}$ to lyses erythrocytes. The splenocytes were washed and resuspended in RPMI 1640 supplemented with $20 \mathrm{mM}$ sodium pyruvate, $5 \times 10^{5} \mathrm{M}$ mercaptoethanol, $4 \mathrm{mM}$ glutamine, $10 \%$ bovine fetal serum, $100 \mathrm{U} / \mathrm{ml}$ penicillin and $100 \mu \mathrm{g} / \mathrm{ml}$ streptomycin. The cell's viability and number were assessed in an improved Newbauer chamber using $0.4 \%$ Trypan blue.

Cytokines assay before and after the challenge infection with L. major

The splenocyte cultures and cytokine assays were performed. Briefly, single-cell preparations from the spleen tissue were plated in duplicate in 24-well plates (Nunc) at 
$2 \times 10^{6}$ cells $/ \mathrm{ml}$. The cells were incubated in DMEM (Dulbecco modified eagle medium ) alone (background control). Then the cells were stimulated in triplicate with soluble L. major antigen separately stimulated with SLA (soluble Leishmania antigen) from L. major $(20 \mu \mathrm{g} / \mathrm{ml})$, at $37{ }^{\circ} \mathrm{C}$ in $5 \% \mathrm{CO}_{2}$ for $48 \mathrm{~h}$. The SLA-stimulated cells presented stimulation indexes in the range of 3.5-3.7 for the spleen cells. SI (Stimulated index) greater than 2.5 indicated a positive response. Levels of IFN- $\gamma$ and IL-4 in the supernatants were assessed by sandwich ELISA (enzyme-linked immunosorbent assay) using Inter Test mouse IFN- $\gamma$ and IL-4. [ELISPOT Kit]. All the tests were performed in triplicate for mice (Rafati et al. 2006).

Detection of antibody responses

before and after the challenge infection with $L$. major

The blood samples were collected by retro-orbital puncture from the immunized mice 3 weeks after immunization and 3 weeks after challenge infection. The samples were centrifuged in 3,000 rpm for $15 \mathrm{~min}$ for serum preparation. The sera were tested for the presence of total anti-L. major IgG antibodies by ELISA. Briefly, the microtitre plates were coated overnight at $4{ }^{\circ} \mathrm{C}$ with soluble $L$. major antigens $(10 \mu \mathrm{g} / \mathrm{ml})$ in $100 \mathrm{mM}$ carbonate-bicarbonate buffer $\mathrm{pH} 9.6$ (100 $\mu \mathrm{L}$ per well) and sealed. The plates were washed in PBS (pH 7.4). Blocking was carried out with $1 \%$ dried skim med milk in PBS (pH 7.2) for $1 \mathrm{~h}$ at $37^{\circ} \mathrm{C}$. After washing with PBS containing $0.05 \%$ Tween 20 (PBST20), the sera were diluted $1 / 200$ in $1 \%$ dried skimmed milk-PBST20 $(100 \mu \mathrm{L}$ per well) and incubated for $1 \mathrm{~h}$ and $30 \mathrm{~min}$ at $37^{\circ} \mathrm{C}$. After washing, the bound antibodies were detected by incubation at $37{ }^{\circ} \mathrm{C}$ for $1 \mathrm{~h}$ and $30 \mathrm{~min}$ with HRP (horseradish peroxidase)-labeled goat anti-mouse IgG (DAKO,Denmark) at $1 / 2,000$ dilution in $1 \%$ dried skimmed milkPBST20 (100 $\mu$ Lper well). Peroxidase activity was revealed by adding $100 \mu \mathrm{L}$ per well of (TMB) tetra methyl benzidine substrate. The reaction was stopped after $15 \mathrm{~min}$ with adding $100 \mu \mathrm{L}$ of $2 \mathrm{MH} 2 \mathrm{SO} 4$ and the (OD) optical density was read at $450 \mathrm{~nm}$ in an ELISA micro plate reader (Bio-Rad,USA). Specific IgG1 and IgG2a subclasses were detected using goat anti mouse IgG1 and IgG2a secondary antibodies (Sigma, USA) according to the manufacture's instruction (Sasaki et al. 2003, Buffer 1995).

\section{Statistical analysis}

Statistical comparisons between the experimental groups were carried out with an analysis of variance (ANOVA) and post hoc Turkey test. Differences were statistically considered significant when $\mathrm{p}$ values was less than 0.05 $(p<0.05)$.

\section{Results}

Our results showed that recombinant protein was produced in the E. coli BL21 (DE3) containing pET 28aTSA plasmid after induction with $1 \mathrm{mM}$ IPTG that expression of recombinant protein was confirmed with SDS page and Western blot analysis (a $\sim 22 \mathrm{kDa}$ band). In the next, we intended that use this protein as a vaccine candidate against Leishmania infection in BALB/c mouse model.

To evaluate the proliferative responses of lymphocytes was used to Brdu test. The 3 weeks after three protein vaccination the proliferative responses of lymphocytes markedly were increased in the vaccinated groups, which were significantly higher than in control group. $(P<0.05)$. Before and after challenge infection in the vaccinated groups were no statistical significant difference but was statistical significant difference with control group (Fig. 1).

We analyzed the levels of IFN- $\gamma$ and IL-4 production in the supernatants of the spleen cells of all the 4 groups 3 weeks after immunization and 3 weeks after challenge infection with $L$. major. The 3 weeks after three protein vaccination IFN- $\gamma$ values markedly increased in the vaccinated groups, which were significantly higher than in the control group $(p<0.05)$. Between vaccinated groups were no statistical significant difference $(p>0.05)$. After challenge infection IFN- $\gamma$ values markedly increased in the vaccinated groups, which were significantly higher than in the control group $(p<0.05)$. Between the vaccinated groups were no statistical significant difference $(p>0.05)$ (Fig. 2). Before booster injection and after challenge with $L$. major IL-4 values significant differences were not observed between vaccinated and control groups $(p>0.05)$. Though before booster injection and after challenge IL-4 values increased in the vaccinated groups but there were no statistically significant differences between vaccinated and control groups $(p>0.05)$ (Fig. 3).The sera were collected from the immunized and control mice 3 weeks after the final booster injection and 3 weeks after the challenge infection, tested for the presence of total IgG antibodies by indirect ELISA method. Figures 4, 5 showed that the humeral responses were elicited by the immunization before and after the challenge infection. Before booster and after challenge anti- $L$. major IgG values markedly increased in TSA/Montanide group, which was significantly higher than in control group $(p<0.05)$ but significant differences were not observed between vaccinated groups. Figures 6, 7 Results of IgG isotyping before and after challenge showed that all vaccine immunized groups significantly increased $\mathrm{IgG1}, \mathrm{IgG} 2 \mathrm{a}$ subclasses as compared to the control group $(P<0.030)$. 
Fig. 1 The proliferative responses of lymphocytes (Brdu test) in vaccinated and control groups

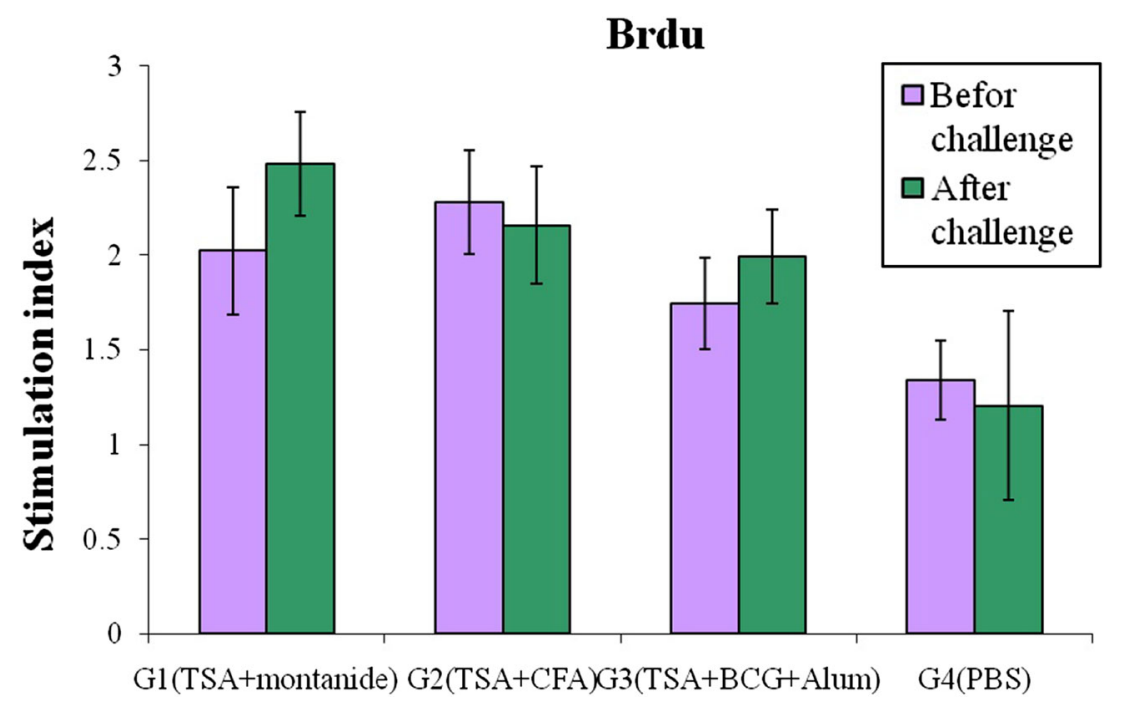

\section{Discussion}

Leishmaniasis is prevalent in many parts of the world, with about 12 million total cases worldwide. As many as $1.5-2$ million new cases of cutaneous leishmaniasis and 5,00,000 cases of visceral leishmaniasis are reported every year (Handman 2001). In view of the emerging drug resistance, the development of safe and efficient vaccines remains to be the best hope for achieving definitive control of leishmaniasis. Immunity against re infection is acquired following cutaneous infection with Leishmania spp., suggesting that prophylactic immunization is feasible. A number of vaccine strategies have been tested, ranging from killed parasites to recombinant antigens or DNA or protein vaccines. No protective and effective anti-Leishmania vaccine is available at the moment in spite of several tested vaccine protocols despite enormous effort of researchers to preparation of effective vaccine formula there is no protective vaccine and this failure turned to cell mediated immune system response in primarily impact to parasite (Handman 2001; Campos-Neto et al. 2001). In this level vaccine progresses strategy against $L$. major depends on proper and good defined antigen (s) and application of strong adjuvant in vaccine formulation to reach optimal immunity results. The availability of hundreds of adjuvants has prompted a need for identifying rational standards for the selection of adjuvant formulation based on immunological principles for human vaccines (Benhnini et al. 2009). TSA family from humans to Saccharomyces cerevisiae has conserved domains and distinctive similarity in amino acid sequence has been seen in this group. $S$. cerevisiae TSA confer safety against oxidative stress and damage. Mechanism of TSA action embedded in a thiol oxidation-based enzyme inhibition mode. Function of TSA protein depend on thioredoxin, thioredoxin reductase, and $\mathrm{NADPH}$ as reducing equivalents, then been define as thioredoxin peroxidase. Thioredoxin as a reducing equivalent In $S$. cerevisiae help to reduction of $\mathrm{H} 2 \mathrm{O} 2$ molecules and participate in protection of mechanism against peroxidemediated oxidative damage Similar situation occurs inside
Fig. 2 Cytokine production $(\mathrm{IFN}-\gamma)$ by the splenocytes in vaccinated and control groups

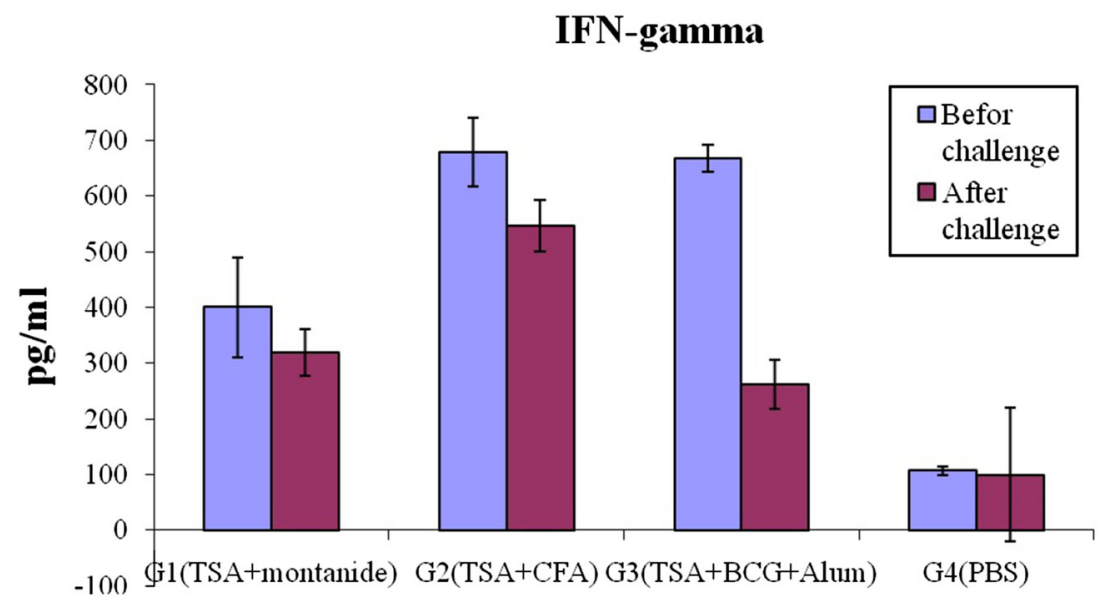


Fig. 3 Cytokine production (Il4) by the splenocytes in vaccinated and control groups

Fig. 4 Production of total $\mathrm{IgG}$ 3 weeks after the last vaccination (before booster injection), all the sera were diluted 1:20 and results are expressed as the $O D$ optical density at $450 \mathrm{~nm}$
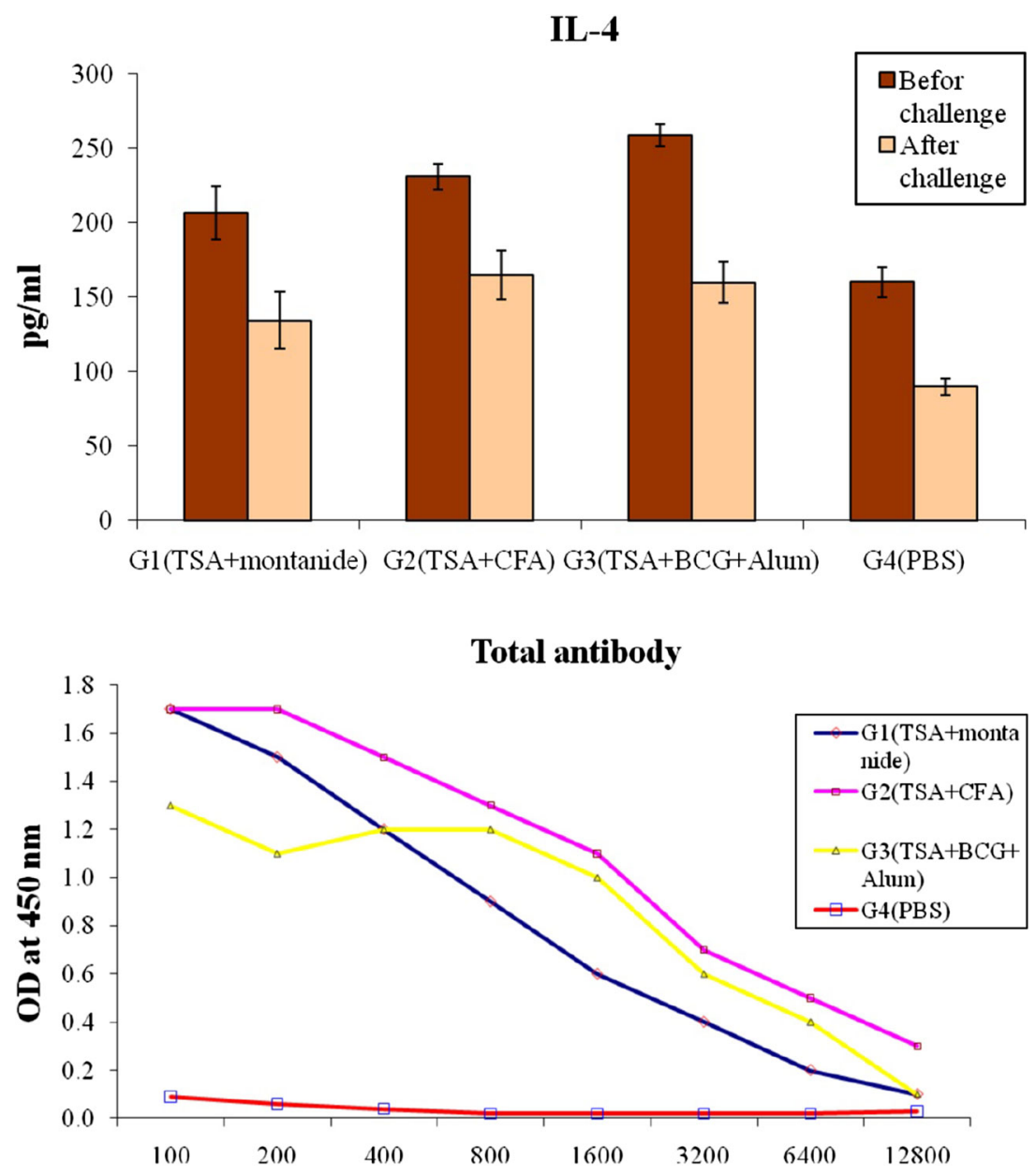

Fig. 5 Production of total $\mathrm{IgG}$ 3 weeks after the booster injection, all the sera were diluted 1:20 and results are expressed as the $O D$ optical density at $450 \mathrm{~nm}$

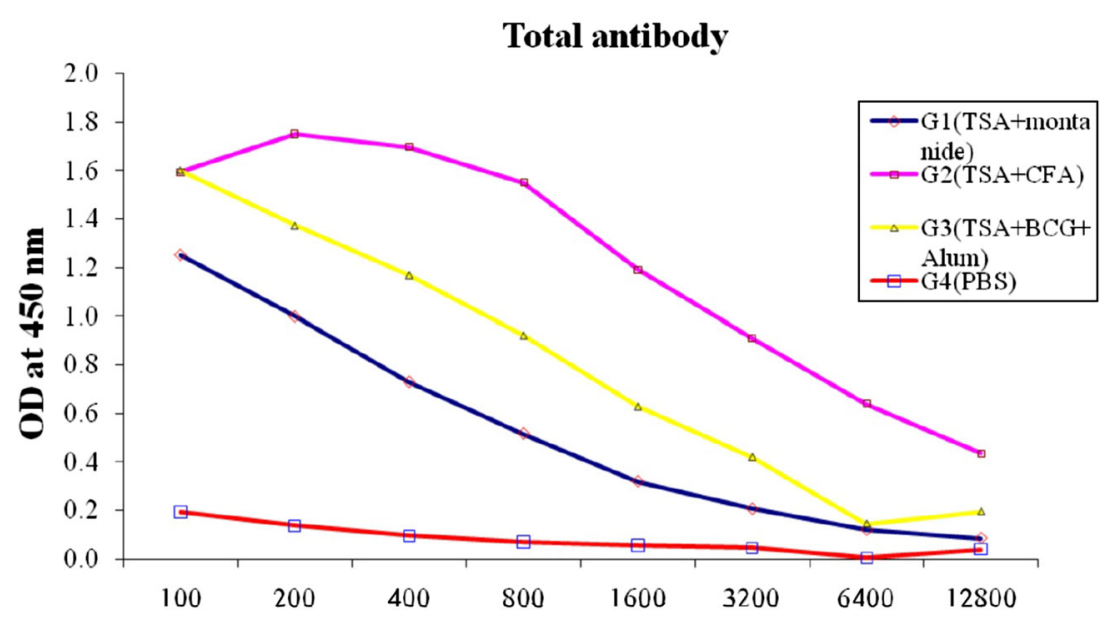

macrophages. Respiratory burst in macrophages mediated by production of $\mathrm{H} 2 \mathrm{O} 2$ and TSA molecules as leishmania product, guarantee Leishmania survival inside the macrophages. (Mendez et al. 2002; Chae et al. 1993, Chae et al. 1994a, b; Netto et al. 1996; James and Nacy 1993; Mehlotra, 1996; Ahmed et al. 2004). The recombinant leishmanial antigens LmSTI1 and TSA have been shown that they can induce excellent protection in both murine and non human primate models of human cutaneous leishmaniasis. The recombinant TSA protein with IL-12 induces excellent protection in the $\mathrm{BALB} / \mathrm{c}$ mice recombinant proteins, LACK and TSA have produced at least partial protection against L. major in BALB/c mice (Ovendale et al. 1998; Mougneau et al. 1995). Successful immunization that induces protection against leishmaniasis is highly dependent on adjuvant that preferentially stimulates 
Fig. 6 Production of IgG1 before and after challenge, all the sera were diluted 1:20 and results are expressed as the $O D$ optical density at $450 \mathrm{~nm}$
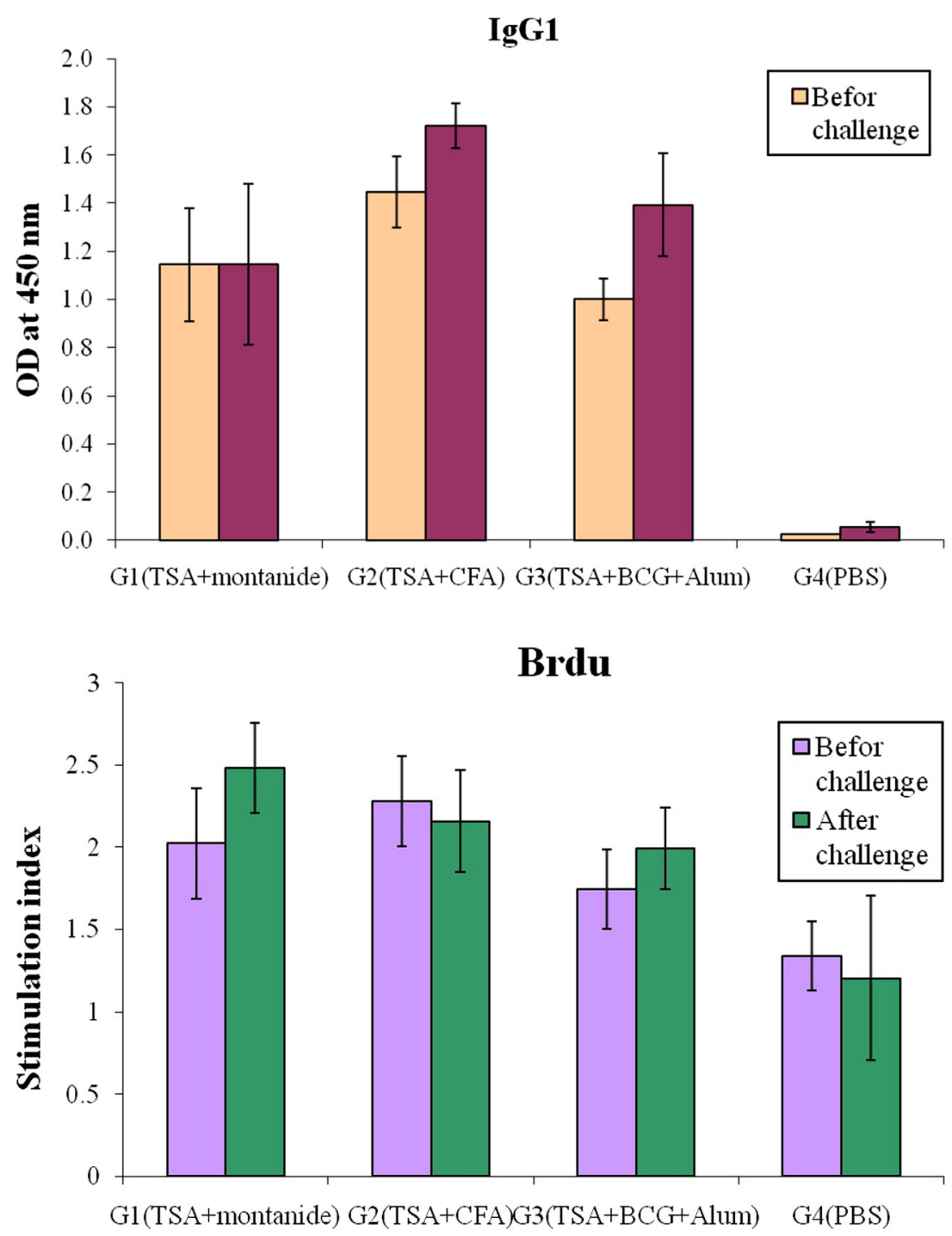

Fig. 7 Production of total $\mathrm{IgG} 2 \mathrm{a}$ before and after challenge, all the sera were diluted 1:20 and results are expressed as the $O D$ optical density at $450 \mathrm{~nm}$ the Th1 phenotype of immune response. In this research was used Montanide ISA 70 as a adjuvant. Montanide ISA 70 has been approved for experimental use in humans as an alternative adjuvant to aluminium hydroxide.It has been shown to be immunogenic, inducing both Th1-type cellular and humoral immune responses in humans. Montanide ISA 70 has also shown good results in non-human primate vaccination studies. A safety and immunogenicity study of a malaria vaccine containing single, intramuscular doses of ICC-1132 formulated in Montanide ISA 720 showed that the vaccine was safe and well tolerated. All vaccines that received either $20 \mu \mathrm{g}$ or $50 \mu \mathrm{g}$ of ICC-1132/ISA 720 developed anti immunogen antibodies, predominantly of opsonizing IgG subtypes. Peripheral blood mononuclear cells of ICC-1132/ISA 720 vaccinees proliferated and released cytokines when stimulated with recombinant Plasmodium falciparum CS protein, and CS-specific CD4 + T cell lines were established from volunteers with high levels of antibodies to the repeat region. (Joshua et al.
2010) Kusakabek et al. showed IFN- $\gamma$ induction vaccinated group (with Montanide) was significantly higher than controls (khoshgoo et al. 2008). Qiu et al. showed that protein immunization using CpG ODN and Montanide ISA 720 as adjuvants greatly enhanced cellular as well as humoral immune responses against $\mathrm{HCV}$ in Balb/c mice and the use of adjuvants appears critical to the induction of Th1 immune responses during HCV vaccination with recombinant proteins (Qiu et al. 2008). In this study our results showed that proliferative responses of lymphocytes and IFN- $\gamma$ values before and after challenge infection in the vaccinated groups were no statistical significant difference but was statistical significant difference with control group but in IL-4 values significant differences were not observed between vaccinated and control groups. Before booster and after challenge anti-L. major IgG values markedly increased in TSA/Montanide group, which was significantly higher than in control group but significant differences werenot observed between vaccinated groups. While 
exploring $\mathrm{IgG}$ isotypes our results revealed that both specific $\operatorname{IgG}_{1}$ and $\operatorname{IgG}_{2 \mathrm{a}}$ were augmented. Considering that $\mathrm{IgG}_{1}$ is a $\mathrm{Th}_{2}$ marker and $\mathrm{IgG}_{2 \mathrm{a}}$ is a Th1 marker, these funding indicated that before and after challenge level of $\mathrm{IgG}_{1}$ and $\mathrm{IgG}_{2 \mathrm{a}}$ isotypes in immunized groups increased. Studies of Campos-Neto et al. showed that immunization of BALB/c mice with a TSA plasmid DNA induced high titers of specific $\operatorname{IgG}_{1}, \operatorname{IgG}_{2 \mathrm{a}}$ antibodies against Leishmania (Campos-Neto et al. 2001, 2002, 2005).

In this study, we demonstrated that Montanide can effect on efficacy of a protein vaccine-encoding TSA against $L$. major infection and elicits humeral and cellular immune responses. The vaccine formulation described here may be an protection and excellent candidate for further vaccine development.

Acknowledgements We would like to thank of Iran University of Medical Sciences and Tehran University of Medical sciences for Financial Supports this work.

Conflict of interest We declare no conflicts of interest.

\section{References}

Ahmed SB, Bahloul C, Robbana C, Askri S, Dellagi KA (2004) Comparative evaluation of different DNA vaccine candidates against experimental murine leishmaniasis due to L.major. Vaccine 22:1631-1639

Alvar J, Velez ID, Bern C, Herrero M, Desjeux P, Cano J et al (2012) Leishmaniasis worldwide and global estimates of its incidence. PLoS One 7:e35671

Aucouturier J, Dupuis L, Ganne V (2001) Adjuvants designed for veterinary and human vaccines. Vaccine 19:2666-2672

Aucouturier J, Dupuis L, Deville S, Ascarateil S, Ganne V (2002) Montanide ISA 720 and 51: a new generation of water in oil emulsions as adjuvants for human vaccines. Expert Rev Vaccines 1:111-118

Benhnini F, Chenik M, Laouini D, Louzir H, Cazenave PA, Dellagi K (2009) Comparative evaluation of two vaccine candidates against experimental leishmaniasis due to Leishmania major infection in four inbred mouse strains. Clin Vaccine Immunol 16:1529-1537

Bradford, MM (1976) A rapid and sensitive method for the quantification of microgram quantities of protein utilizing the principle of protein-dye binding. Anal Biochem 72:248-254

Buffer PA, Sulahian A, Garin YJF, Nassar N, Derouin F (1995) Culture microtitration :a sensitive method for quantifying Leishmania infantum in tissues of infected mice. Antimicrob Agents Chemother 216:7-8

Campos-Neto A (2005) What about Th1/Th2 in cutaneous leishmaniasis vaccine discovery? Braz j Med Biol Res = Revista brasileira de pesquisas medicas e biologicas/Sociedade Brasileira de Biofisica [et al]; 38:979-984

Campos-Neto A, Porrozzi R, Greeson K, Coler RN, Webb JR, Seiky YA et al (2001) Protection against cutaneous leishmaniasis induced by recombinant antigens in murine and nonhuman primate models of the human disease. Infect Immun 69:4103-4108
Campos-Neto A, Webb JR, Greeson K, Coler RN, Skeiky YA, Reed SG (2002) Vaccination with plasmid DNA encoding TSA/ LmSTI1 leishmanial fusion proteins confers protection against Leishmania major infection in susceptible BALB/c mice. Infect Immun 70:2828-2836

Chae HZ, Kim IH, Kim K, Rhee SG (1993) Cloning, sequencing, and mutation of thiol-specific antioxidant gene of Saccharomyces cerevisiae. J Biol Chem 268:16815-16821

Chae HZ, Chung SJ, Rhee SG (1994a) Thioredoxin-dependent peroxide reductase from yeast. J Biol Chem 269:27670-27678

Chae HZ, Robison K, Poole LB, Church G, Storz G, Rhee SG (1994b) Cloning and sequencing of thiol-specific antioxidant from mammalian brain: alkyl hydroperoxide reductase and thiolspecific antioxidant define a large family of antioxidant enzymes. Proc Natl Acad Sci U S A 91:7017-7021

Coler, RN, Reed, SG (2005) Second-generation vaccines against leishmaniasis. Trends Parasitol 21:244-249

Douba MD, Abbas O, Wali A, Nassany J, Aouf A, Tibbi MS et al (2012) Chronic cutaneous leishmaniasis, a great mimicker with various clinical presentations: 12 years experience from Aleppo. J Eur Acad Dermatol Venereol 26:1224-1229

Farahmand M, Nahrevanian H, Shirazi HA, Naeimi S, Farzanehnejad $Z$ (2011) An overview of a diagnostic and epidemiologic reappraisal of cutaneous leishmaniasis in Iran. Braz J Infect Dis 15:17-21

Handman E (2001) Leishmaniasis :current status of vaccine development. Clin Microbiol Rev 14:229-243

James SL, Nacy C (1993) Effector functions of activated macrophages against parasites. Curr Opin Immunol 5:518-523

Joshua MM, John CM, Michael MG (2010) A review of adjuvants for leishmania vaccine candidates. J Biomed Res 24:16-25

Khamesipour A, Rafati S, Davoudi N, Maboudi F, Modabber F (2006) Leishmaniasis vaccine candidates for development: a global overview. IndianJ Med Res 123:423-438

Khoshgoo N, Zahedifarda F, Azizia H, Taslimia Y, Alonsoc MJ, Rafati S (2008) Cysteine proteinase type III is protective against Leishmania infantum infection in BALB/c mice and highly antigenic in visceral leishmaniasis individuals. Vaccine 26:5822-5829

Masina S, Gicheru MM, Demotz SO, Fasel NJ (2003) Protection against cutaneous leishmaniasis in outbred vervet monkeys using a recombinant histone H1 antigen. J Infect Dis 15:1250-1257

Mauel J (2002) Vaccination against Leishmania infections. Curr Drug Targets Immune Endocr Metabol Disord 2:201-226

Mehlotra, RK (1996) Antioxidant defense mechanisms in parasitic protozoa. Crit Rev Microbiol 22:295-314

Mendez S, Belkaid Y, Seder RA, Sacks D, Sender R (2002) Optimization of DNA vaccination against cutaneous leishmaniasis. Vaccine 20:3702-3708

Mougneau E, Altare F, Wakil AE, Zheng S, Coppola T, Wang ZE et al (1995) Expression cloning of a protective Leishmania antigen. Science 268:563

Netto, LES, Chae,H.Z, Kang, SW, Rhee,S.G, Stadtman, ER (1996) Removal of hydrogen peroxide by thiol-specific antioxidant enzyme [TSA] is involved with its antioxidant properties. TSA possesses thiol peroxidase activity. $J$ Biol Chem 271:15315-15321

Ovendale PJ, Martin TI, Webb JR, Campos-Neto A, Reed SG, Badaro $\mathrm{R}$ et al (1998) Human and murine immune responses to a novel Leishmania major recombinant protein encoded by members of a multicopy gene family. Infect Immun 66:3279-3289

Qiu Q, Yuan-HuWang R, Jiao X, Jin B, Sugauchi F, Grandinetti T et al (2008) Induction of multispecific Th-1 type immune response against $\mathrm{HCV}$ in mice by protein immunization using $\mathrm{CpG}$ and Montanide ISA 720 as adjuvants. Vaccine 26:5527-5534 
Rafati S, Zahedifard F, Nazgouee F (2006) Prime-boost vaccination using cysteine proteinases type I and II of Leishmania infantum confers protective immunity in murine visceral leishmaniasis. Vaccine 24:2169-2175

Rosado-Vallado M, Mut-Martin M, Garsia-Miss M, Dumonteil E (2005) Aluminium phosphate potentiates the efficacy of DNA vaccine against Leishmania Mexicana. Vaccine 23:5372-5379

Sasaki S, Takeshita F, Xin KQ, Ishii N, Okuda K (2003) Adjuvant formulation and delivery systems for DNA vaccines. Methods $31: 243-254$

Tabatabaie F, Ghaffari far F, Dalimi A, Sharifi Z, Zavaran Hoseini A (2007) Cloning and sequencing of leishmania major thiolspecific antioxidant antigen [TSA] gene. Iran J Parasitol 2:30-41
Toledo H, Baly A, Castro O, Resik S, Laferte J, Rolo F et al (2001) A phase I clinical trial of a multi-epitope polypeptide TAB 9 combined with Montanide ISA720 adjuvant in non-HIV-1 infected human volunteers. Vaccine 19:4328-4336

Von Stebut E (2007) Immunology of cutaneous leishmaniasis: the role of mast cells, phagocytes and dendritic cells for protective immunity. Eur J Dermatol 17:115-122

Webb JR, Campos-Neto A, Ovendale PJ, Martin TI, Stromberg EJ, Badaro R et al (1998) Human and murine immune responses to a novel Leishmania major recombinant protein encoded by members of a multicopy gene family. Infect Immun 66:32793289 